\title{
MASCULINIDADES HEGEMÔNICAS E DISSIDÊNCIAS: TENSÕES CURRICULARES EM COTIDIANOS DE ESCOLAS DA PERIFERIA
}

\author{
Marcio Rodrigo Vale Caetano ${ }^{1}$ \\ Paulo Melgaço da Silva Junior ${ }^{2}$ \\ Treyce Ellen Silva Goulart ${ }^{3}$
}

\section{Resumo}

As identidades (sexuais), em sua relação com o espaço escolar estão, a todo tempo, tensionando e sofrendo a interpelação dos currículos. Considerando esse cenário, a partir das contribuições das teorias de gênero e sexualidades e da metodologia de Observação Participante, esse artigo objetivou questionar os modos como as masculinidades hegemônicas de duas escolas públicas da região da Baixada Fluminense do Rio de Janeiro são performatizadas e interagem com as identidades sexuais dissidentes, a exemplo de gays, travestis e transexuais (GT). Com os dados que subsidiaram a análise, produzidos a partir de práticas docentes dos autores, buscou-se questionar os currículos com vistas a interrogá-los sobre os discursos que produziram modos de subjetivação e ensinaram formas heteronormativas, complementares e assimétricas de projeção das identidades sexuais fortemente atravessadas pelas expectativas em torno da(s) masculinidade(s) negra(s).

Palavras-chave: Currículos; Performances; Masculinidades; Dissidências

\footnotetext{
${ }^{1}$ Doutor em educação pela UFF (2011). Endereço: Rua Benjamin Constant, 1708, apto 403, Centro, Pelotas/RS, CEP 96010-020, Brasil. Endereço eletrônico: mrvcaetano@ gmail.com

${ }^{2}$ Doutor em Educação pela UFRJ (2014). Endereço: Rua Barão de Itapagipe 71/1406 bl 2. Bairro Rio comprido, CEP: 20261-005, Brasil. Endereço eletrônico: pmelgaco@uol.com.br

${ }^{3}$ Mestre em Educação pela FURG (2016). Endereço: Av. Brasil, 348, bairro Bucchholz, CEP: 96212-150, Rio Grande/RS, Brasil. Endereço eletrônico: treyce.ellen@ hotmail.com
} 


\section{INTRODUÇÃO}

Este texto objetiva debater as performances hegemônicas assumidas pelas masculinidades de estudantes entre 10 e 18 anos e como elas interagem com as identidades sexuais dissidentes, a exemplo de gays e travestis. Os dados que subsidiaram a análise foram produzidos a partir das ações promovidas pelos autores deste artigo em escolas públicas de Ensino Fundamental localizadas nas periferias das cidades de Belford-Roxo e Duque de Caxias - arrabaldes da região metropolitana do Rio de Janeiro.

Para efeito de nomeação, a escola de Duque de Caxias será chamada de "Nós do Morro" e a de Belford-Roxo, "Escola Vozes". Elas atendem cerca de 1300 estudantes de baixa renda ${ }^{4}$ e seu público caracteriza-se pela forte presença da população negra de origem nordestina ${ }^{5}$. Não diferente das características gerais da população discente das escolas e das localidades, os sujeitos discentes da pesquisa são majoritariamente negros, de baixa renda e a faixa etária varia entre 11 e 18 anos. Vale destacar que foram selecionados e problematizados os fragmentos de narrativas de 6 (seis) estudantes que, na opinião das pessoas pesquisadoras, exemplificavam de forma mais contundente os eixos aqui analisados. Felipe, Daniel, Luan, Dayse, Pedro e João são nomes (auto)atribuídos quando lhes foi informado sobre a escrita deste artigo ${ }^{6}$.

Os dados que subsidiaram essa análise foram produzidos por meio da Observação Participante. Tal abordagem metodológica reconhece a pessoa pesquisadora enquanto um instrumento de investigação e requer um contato direto e prolongado com o contexto analisado. Além disso, ela se complementa com a entrevista ou análise documental. Com Correia (2014), entendemos como Observação Participante a totalidade do trabalho de campo, desde a chegada das pessoas investigadoras ao contexto de pesquisa, compreendendo as negociações necessárias para conseguir acesso a este, as visitas prévias e a observação/interação com os indivíduos envolvidos. A essas etapas, inicialmente marcadas

\footnotetext{
${ }^{4}$ Segundo o Decreto Presidencial n 6135, de 26 de junho de 2007, considera-se família de baixa renda aquela com renda familiar mensal per capita de até meio salário mínimo ou a que possua renda familiar mensal de até três salários mínimos. Disponível em: http://www.planalto.gov.br/ccivil_03/_ato20072010/2007/Decreto/D6135.htm. Acesso em: 12 mar. 2016.

${ }^{5}$ Censo escolar de 2014, produzido pela equipe diretiva das escolas. Dada as dimensões éticas e a garantia do anonimato, os documentos não serão citados nas referencias. Entretanto, Silva Jr. (2014) e Caetano (2011) farão as mesmas afirmações quanto ao perfil populacional das escolas.

${ }^{6}$ Ainda que tenhamos o termo de consentimento livre e esclarecido dos/as entrevistados/as e seus responsáveis, em virtude de que os autores atuam ou atuaram nas escolas pesquisadas e que as experiências narradas são identificáveis, as escolas e suas personagens serão ficticiamente referenciadas.
} 
por uma fase mais descritiva e na qual o/a observador/a constrói uma visão geral, segue-se um maior aprofundamento/seletividade nas várias observações. Ao fim, no decurso da elaboração de um relatório, devem ser apuradas as observações para a produção efetiva dos dados.

Assim sendo, orientados pela Observação Participante, foram utilizadas três técnicas de produção de dados, quais sejam: (a) interação participativa nos cotidianos escolares nos anos de 2014 e 2015; (b) anotações de conversas informais consideradas significantes nos contextos das escolas e (c) entrevistas semiestruturadas com os indivíduos, orientadas por eixos que tinham como interesse as experiências escolares que interseccionam gênero, sexualidades e masculinidade(s).

Para efeito de orientação ao/à leitor/a, o artigo foi estruturado em três seções: na primeira, propomo-nos a debater algumas das produções acadêmicas acerca das temáticas "gênero", "sexualidades" e "masculinidade(s)", buscando, com isso, aproximá-las da educação escolar para, na segunda seção, proceder à análise dos dados da pesquisa. $\mathrm{Na}$ terceira e última seção, apresentamos as conclusões.

\section{ASPECTOS TEÓRICOS}

A adolescência se caracteriza como um período de desenvolvimento marcado por intensas transformações biopsicossociais impulsionadas pelas experiências culturais e pelas mudanças hormonais da puberdade. Ainda que sobre o tema resida um complexo emaranhado discursivo, a adolescência constitui-se, no geral, como uma fase de transição entre os anos da vida infantil e a adulta. Nesse período, é observado acentuado desenvolvimento corporal, vivências emocionais, construções de redes interpessoais de amizades etc., que interpelam a identidade, assumindo performances e mediando a construção de redes de sociabilidades (SCHOEN-FERREIRA, 2010). Dentre as inúmeras modificações vivenciadas na adolescência, sem dúvida, uma das mais significativas está relacionada à sexualidade.

Ainda que seja indeterminado o período cronológico que dará conta das transformações do corpo na adolescência, no geral, elas acentuam-se entre os 10 e 16 anos. Porém, os limites cronológicos da adolescência são definidos pela Organização Mundial da Saúde (OMS, 1986) entre 10 e 19 anos. No Brasil, o Estatuto da Criança e do Adolescente (ECA), instituído pela Lei Federal nº 8.069 de 1990, considera criança a pessoa de até 12 anos de idade incompletos e define a adolescência como a faixa etária de 12 a 18 anos (Art. 2) 
MASCULINIDADES HEGEMÔNICAS E DISSIDÊNCIAS:

TENSÕES CURRICULARES EM COTIDIANOS DE ESCOLAS DA PERIFERIA

e, em casos excepcionais e quando disposto em lei, o Estatuto é aplicável até os 21 anos de idade (Art. 121 e 142). Portanto, independentemente da perspectiva, o período da adolescência e toda a profusão sexual que ele acarreta é vivido, quando respeitada a legislação brasileira, na escola.

Hegemonicamente, o sexo vem sendo entendido pelo discurso biológico como o conjunto de características genéticas, anatômicas e hormonais que distinguem os indivíduos heterodesignados como machos ou fêmeas (RODRÍGUEZ, 1994). Essa mesma palavra também é correntemente usada para nomear o órgão anatômico sexual e a relação genital entre pessoas. Contudo, neste artigo, com o auxílio de Butler (2003), entenderemos sexo, assim como a categoria "gênero", como um feito social marcado pelo significado cultural e não simplesmente um ato natural, uma anatomia corporal ou uma função biológica de caráter reprodutivo entendido e massificado hegemonicamente pelas ciências médico-biológicas, inclusive nas escolas.

A compreensão assumida, como sublinhado por Butler (2003), é reforçada quando consideramos a análise feita por Foucault (1988), ao destacar o caráter normativo do sexo. Para ele, o sexo é um "ideal regulatório" que não só funciona como norma, mas é parte de uma prática reguladora que produz o que governa: o corpo. Ele se caracteriza enquanto um ato performativo cuja força se manifesta como uma espécie de poder produtivo que atravessa a subjetividade dos indivíduos e se materializa em seus comportamentos e entendimentos de si.

O sexo tem o poder de produzir os contornos, os limites e as diferenças nos corpos que controla. Em outras palavras, ele é um processo mediante o qual as normas reguladoras e educativas materializam no corpo as legibilidades socioculturais do sexo e ele, por sua vez, desenvolve sua materialidade em virtude da reiteração forçada de uma norma dicotômica sexual. Nessa perspectiva, o sexo não é apenas uma dimensão pessoal, ela é uma questão política que as sociedades usam para organizar culturalmente os indivíduos nos jogos identitários (CAETANO, 2011). Por outro prisma, Pennycook (2007) aproxima às reflexões sobre identidades, o conceito de performance. Para ele, as performances são produzidas através da repetição de gestos, falas etc., que reforçam a ideia de que existe uma essência e/ou um modo pré-estabelecido de "ser".

Na performance, o indivíduo passa a acreditar no que está dizendo ou fazendo para convencer a audiência. Esses argumentos são reiterados de alguma forma na categoria 
“performatividade de gênero" proposta por Butler (2003). Para a estadunidense, a identidade é um emaranhado de atos linguísticos performativos em que o discurso tem o efeito de materializar e de criar nos corpos a inteligibilidade social. Assim, para Butler (2003), Caetano (2011) e Pennycook (2007) não existe um "ser" anterior às marcas da linguagem em nossas subjetividades. Quer dizer, no caso específico de Butler (2010), não é que a materialidade seja negada - o que seria um absurdo, mas, ao contrário, que a própria materialidade somente pode ser recuperada por meio do discurso, por meio da ação da linguagem. Nessas dinâmicas, por meio da linguagem e de seus símbolos, o poder se consolida e se perpetua, porque ele cria o conceito de verdade dos sexos, naturalizando determinadas situações ou questões e repugnando outras, passando, dessa forma, a produzir significados, auxiliando a criação do que é denominado senso comum.

Segundo Moita Lopes (2002), uma sociedade normalizadora é o efeito histórico de uma tecnologia de poder centrada na vida. Essas normas ou códigos são aplicados de forma sutil, de modo que tornam aceitável um poder essencialmente normatizador. Nessa direção, Caetano (2011) observa que os grupos que ocupam posições sociais de normalidade têm a possibilidade não apenas de se autorrepresentarem, como também de elaborarem e nomearem a representação de outros. Se concordamos com a afirmação do autor, as representações (que produzem efeitos políticos) de "anormalidade" e "doença" nascem do ponto de vista daquele/a que, ocupando a posição de normalidade, define, através de suas instituições, a exemplo da ciência, o comportamento padrão. E esse quadro produz efeitos também nos currículos escolares.

Sobre currículo, Moreira (1997) assinala que o conceito está relacionado a uma complexidade de problemas e a uma determinada construção cultural, histórica e social. Porém, conforme ressalta o autor, as definições de currículo, geralmente, são desenhadas a partir de noções de conhecimento escolar e de experiência de aprendizagem. No interior do enfoque de conhecimento escolar, que tem predominado ao longo dos tempos, o currículo é o conhecimento tratado pedagógica e didaticamente pela escola e que deve ser aprendido e aplicado pelo/a discente. É nesse caminho que surgem questões sobre o que o currículo deve eleger e como ele deve estruturar os conteúdos. Já no enfoque de experiência de aprendizagem, currículo passa a significar o conjunto de experiências a serem vividas pelo/a estudante sob a orientação da escola. Entendendo que o corpo é lócus de produção e expressão da cultura no qual a sexualidade e o gênero são significados, os currículos ganham 
importância por serem um dos dispositivos que, na escola, atravessam a formação de seus indivíduos.

Debater currículo, portanto, é direcionar ao centro de nossas questões as intencionalidades e os princípios referenciais que orientam a escola, já que, de acordo com Arroyo (2011), a escola e os conhecimentos curriculares estão no meio das disputas políticas que ocorrem em torno das identidades. Nesse sentido, a ideia de conhecimento nos currículos como um artefato relativamente neutro, tornando-o apenas um processo psicológico que se estabelece através da cognição, tem permitido uma falaciosa e letal despolitização quase integral da cultura eurocentrada, branca, judaico-cristã, colonizada, burguesa e heterossexual que as escolas universalizam através de suas práticas pedagógicas cotidianas. Para além de questionarmos os currículos e os conhecimentos universalizados por meio dele, deveríamos perguntar: a quem pertence a cultura que majoritariamente elabora os currículos? A que grupo social referenciam os saberes difundidos com/pela a escola?

Como demarca Silva (1999), nas teorias do currículo, a pergunta “o quê?” nunca está separada de outra indagação: "O que os e as estudantes devem ser?", ou melhor, "o que devem se tornar?". Sob a lógica racional de organização dos conteúdos e das práticas intencionais da escola, o currículo busca precisamente modificar ou formar os sujeitos para a vida ocupacional e em sociedade na fase adulta. De forma mais ampla, o conjunto de teorias do currículo deduzem o modelo de conhecimento importante a partir de descrições sobre o tipo de indivíduo que elas consideram ideal para constituir a sociedade e garantir o seu planejamento e os seus princípios de cidadania. Nesses jogos de poder originam-se os silêncios em torno das identidades sexuais dissidentes, a exemplo de gays, travestis e transexuais, que se aprofundam, quando os cruzamos com as dimensões de gênero, raça/etnia e classe.

Essas considerações se inserem em um momento de alterações substanciais nos discursos científicos que, por sua vez, não estão ausentes dos debates políticos que envolvem o contexto de movimentos sociais emergentes. Ao ponderar o gênero, as identidades sexuais, a raça/etnia e a classe como questões a interrogar, em vez de fatores, por si, explicativos, essas conceituações correspondem, no plano prático-teórico-prático, ao propósito de alocar a questão das diferenças no interior da agenda das investigações acadêmicas e da elaboração de marcadores para as políticas públicas e para os currículos escolares. 
CAETANO, M. R. V.; JUNIOR, P. M. S.; GOULART, T. E. S.

Assim, no leque de teorias apresentadas, as perguntas sobre o tipo de indivíduo desejável para um determinado tipo de sociedade são oportunas para pensar em que posições nos currículos estão os saberes e as narrativas daqueles e daquelas que subvertem as performances e/ou posições hegemônicas sexuais, étnico-raciais e de classe. Ainda que saibamos que, cotidianamente, disputam saberes nas escolas, as tentativas de orientá-las por uma determinada perspectiva são refletidas em suas dinâmicas didático-curriculares.

Esse quadro faz-nos pensar as escolas como espaços em que disputam a perspectiva monocultural e as narrativas e memórias dos coletivos que historicamente foram subalternizados. Conforme Arroyo (2011), nessas relações de disputa, o silenciamento das vozes destoantes do discurso central tem como objetivo a (re)produção de indivíduos com aquelas características desejáveis do ponto de vista do funcionamento social normalizado e hegemônico.

Ao questionar o tipo de indivíduo que deve comportar a sociedade, Silva (1999, p. 15) pergunta:

Será a pessoa racional e ilustrada do ideal iluminista de educação? Será a pessoa otimizadora e competitiva dos atuais modelos neoliberais de educação? Será a pessoa ajustada aos ideais de cidadania do moderno estado-nação? Será a pessoa desconfiada e crítica dos arranjos sociais existentes preconizada nas teorias educacionais críticas?

Cada pergunta leva, em si, para uma determinada performance e corresponde a determinados tipos de saberes da organização didático-curricular. Ao entrever a lógica que operou a elaboração das perguntas feitas por Silva (1999), outras perguntas emergem: quais as táticas criadas pelos indivíduos para subverter as lógicas normatizadoras nas escolas? Sobre quais modelos de mulheres e homens, presentes nas várias teorias pedagógicas, os indivíduos, na escola, criam suas subversões? Como os currículos se rearranjam frente às táticas criadas pelos indivíduos na escola? Como as dissidências interpelam os currículos?

Se nos orientamos pela noção de construção social, as performances estão diretamente relacionadas às maneiras pelas quais os sujeitos se relacionam com outros e com as práticas nas quais se envolvem. Para além disso, são constituídas nos contextos em que estão inseridas, a partir dos quais os significados serão dados e entendidos (PENNYCOOK, 2007).

Nesse sentido, as considerações de Britzman (1996) são esclarecedoras. A autora assinala que toda identidade sexual é um construto instável, mutável e volátil, uma relação social contraditória e não finalizada, sendo constantemente rearranjada, desestabilizada e desfeita pelas complexidades das experiências vividas, ou seja, é uma performance assumida 
MASCULINIDADES HEGEMÔNICAS E DISSIDÊNCIAS:

TENSÕES CURRICULARES EM COTIDIANOS DE ESCOLAS DA PERIFERIA

pelo indivíduo. Bauman (2005, p. 91) contribui com esse pensamento sugerindo que "assumimos uma identidade num momento, mas muitas outras, ainda não testadas, estão na esquina" esperando que as escolhamos.

Pensar em performances identitárias significa abrir um leque de maneiras segundo as quais as pessoas vivem e se apresentam socialmente (BRITZMAN, 1996). Portanto, a construção das performances identitárias solicita um projeto pedagógico-curricular que se encarregue de interpelar e produzir efeitos nos indivíduos. Arriscamos afirmar, com os dados desta pesquisa, que diversas escolas estão empenhadas em construir uma heterossexualidade assimétrica e complementar.

\section{EXPERIÊNCIAS E SABERES COM A ESCOLA: TENSÕES E APRENDIZAGENS COTIDIANAS}

No sentido de problematizar as práticas curriculares em torno da produção de noções hegemônicas ou dissidentes de gênero e sexualidades, apresentaremos algumas narrativas de experiências escolares vividas pelos autores deste artigo, selecionadas a partir dos registros dos diários elaborados durante a Observação Participante nas escolas "Vozes" e "Nós do Morro".

\section{Cena 1:}

Na Escola Vozes, em Belford-Roxo, dois alunos do $9^{\circ}$ ano, apoiados por diversos/as colegas de turmas, se apresentam à direção reivindicando o mesmo direito dos casais heterossexuais de andar de mãos dadas e de se beijar no ambiente escolar. Apesar da dupla ter sofrido muitas críticas negativas, principalmente dos alunos do sexo masculino, eles conseguiram provocar uma grande inquietação, incômodo e discussões no cotidiano da escola. Como resultado, a direção proibiu qualquer manifestação de namoro, seja entre casais heterossexuais seja entre casais homossexuais.

\section{Cena 2:}

Na Escola Nós do Morro, em Duque de Caxias, um aluno de 16 anos é posto para dormir fora de casa. Ao saber disso, a diretora procura a mãe para conversar sobre a questão. Ao voltar para a escola, a diretora diz aos/às professores/as: - A mãe é uma senhora muito trabalhadora, sustenta a família sozinha, a atitude dela foi apenas para ajudar 0 filho. Só está fazendo isso, para ver se o filho aprende a se tornar homem. Ele está andando com gays e ela tem medo de que ele se desvie. Para encerrar a conversa, a diretora pergunta: - Qual mãe quer um filho gay? 


\section{Cena 3:}

Dois alunos de 15 anos da Escola Vozes conversam com o professor sobre uma garota: Olha, comigo é assim, Professor, eu mando logo ver... eu pego direto. Olha aqui (mostrando sua cor)... sou negão, brincou, eu tô [sic] pegando.

Esses episódios são acontecimentos que ocorrem de diferentes maneiras em diversas escolas do país. Na primeira cena narrada, a escola decide pela igualdade, ao proibir qualquer manifestação romântico-afetiva dentro da instituição. Como se, com esse ato, eximisse-se e reafirmasse o discurso de que, cabendo à escola apenas universalizar o que exige o currículo oficial, ela não se configure enquanto espaço para discussão ou experiência em torno das sexualidades.

Ao concordarmos com Caetano (2011), acreditamos que todos os gestos, artefatos e relações estabelecidas na escola educam e compõem os movimentos curriculares. Nessa direção, compreendemos que, com a proibição, a escola, por um lado, educou para uma sexualidade heteronormativa e, ao mesmo tempo, tornou-se mais um lugar em que a homossexualidade é reafirmada no espaço da diferença a ser rejeitada.

Nas interações vividas nas escolas, distintas masculinidades se entrelaçam e se atravessam. Entretanto, o discurso predominante entre os rapazes é o da masculinidade hegemônica. Devemos ressaltar que pensar em masculinidade hegemônica é pensar em uma versão de algo que foi criado, construído, imaginado, considerado como padrão e disseminado a partir do discurso e que, a cada momento, busca ser consolidado nas performances de masculinidades (SILVA JR, 2014). Por outro lado, conforme nos sugere a terceira cena, a essas relações não escapam daquilo que poderíamos chamar de "masculinidades subalternas", as quais se fundariam na intersecção entre masculinidade e marcadores de diferença, tais como classe, raça/etnia e, até mesmo, identidade de gênero, posto que, conforme alertou Halberstam (2008), “masculinidades femininas" são, também, possíveis. Nessa direção, se o núcleo das relações sexuais de gênero é a violência de gênero e a abjeção/dominação ao feminino enquanto afirmação da masculinidade, aos homens negros não há, discursivamente, outra alternativa para a afirmação de sua humanidade a não ser a ratificação de uma performance masculina hegemônica.

É importante ressaltarmos a concepção de que a lógica binária de pensamento não começa ou termina nas relações sociais sexuais entre mulheres e homens, mas encontra-se transversalizada no conjunto da sociedade. Por essa razão, ratificamos o dito por Welzer-Lang (2001), quando esse afirma a existência de um duplo poder na estrutura funcional da 
masculinidade: sobre mulheres e sobre homens. Ou seja, o constructo social que concebemos como ideal, cujo centro é ocupado pelo sujeito universal (homem, branco, heterossexual, cristão e proprietário), tem como eixo central a subjugação dos corpos femininos e das masculinidades subalternas, como, por exemplo, a de homens negros.

Nesses termos ideais, o que as cenas escolares nos permitem apreender é que as dissidências ameaçam a performance estruturada e estruturante da heteronormatividade e sobre elas devem ser aplicadas forças que as adequem aos princípios estabelecidos pela norma social, tornando-as coerentes e legíveis à normalidade. Assim, a narrativa do estudante nos supõe a tentativa de que esses corpos, ao não possuírem a possibilidade de dissimular totalmente sua negritude, pois fenotípica, se autoafirmem a partir de elementos que, dentro de relações coloniais de poder, retroalimentam os discursos que os subalternizam.

Nos corredores, nos pátios e nas salas de aula das escolas em que se desenvolveram essa investigação, podemos observar jovens rapazes, em sua maioria negros, com idades que variam entre 10 e 18 anos, desenvolvendo performances de masculinidades hegemônicas ${ }^{7}$, destacando sempre a presença do falo através de sua manipulação, a força física demonstrada com os músculos e a virilidade comprovada pelo número e exibição de namoradas. Ao mesmo tempo, as brincadeiras, significadas como masculinas, se apresentaram, nas escolas, em uma linha muito tênue entre a violência física e a exibição de força e coragem, fato que se encontra com a afirmativa de Connell (1995) de que o gosto pelos esportes e a representação da força são performances reivindicadas pelos homens, em geral, para evidenciar socialmente suas masculinidades.

$\mathrm{Na}$ "Escola Vozes", independentemente da idade, nas aulas com atividades esportivas e recreativas, podemos ver diversas brincadeiras e jogos de medir força, nos quais os jovens se abraçam e se tocam sem gerar suspeita e dúvida sobre suas performances masculinas. Nas nossas interações, percebemos que as maneiras de convivência entre os meninos destacam um interessante aspecto na amizade entre eles: ainda que os garotos pareçam não valorizar uma amizade orientada pelo toque corporal ou intimidade, organizam-se em grupos.

Independentemente da escola, os estudantes, quando em grupos, apresentavam elementos de competitividade, agressividade e violência. Esse quadro nos aproxima das

\footnotetext{
${ }^{7}$ O conceito de hegemonia elaborado por Antonio Gramsci (1978), apropriado e relido por inúmeros/as autores e autoras, permite ver o campo social como um espaço em que grupos dominantes se veem obrigados a esforços permanentes de convencimento ideológico com o fim de manterem suas dominações. Esse quadro denuncia que, no interior da hegemonia, coexistem inúmeros outros grupos.
} 
afirmações, feitas por Badinter (1993), de que os diversos adolescentes faziam questão de exaltar a virilidade e a força como forma de destacar a masculinidade e afastar de si qualquer dúvida sobre sua performance. Assim pensamos que as masculinidades são práticas diárias nas quais os garotos se engajam e precisam, a todo o momento, negar qualquer aproximação com as marcas que "tatuam" os corpos femininos. Da mesma forma, a partir da noção de dupla dominação, sugerida por Welzer-Lang (2001), a performance masculina deve opor-se àquelas dissidentes que colocam em dúvida a hegemonia, conforme descreve Daniel, 17 anos, da "Escola Vozes":

Tem um rapaz da turma que sofre, coitado! Nunca falei com ele, não quero que aconteça comigo o que está acontecendo com ele. Na hora da chamada a galera cai na pele dele, 0 seu número é o $24^{8}$. É só a professora mencionar o número que a galera logo fala: responde, Paulo. A professora não está nem aí, acho que ela age como se não estivesse entendendo o que está acontecendo. Outro dia Carlos (namorado de Daniel) foi me buscar na escola, preferi sair sem me despedir.

Com a narrativa do estudante, constatamos que as práticas pedagógicas escolares reiteram a violência quando não problematizam as ações que infringem a integridade de seus sujeitos. A necessidade de camuflagem utilizada por Daniel, ocasionada pela violência vivida por Paulo, dificulta a possibilidade de construção de rede de amizade entre estudantes dissidentes nas escolas.

A observação realizada nas escolas "Nós do Morro" e "Vozes" evidenciou que, raramente, os/as alunos/as assumidos/as, independentemente de serem gays, lésbicas, transexuais ou travestis, compartilham espaços com outros estudantes. Além disso, com os relatos, foi possível constatar que a proximidade com o indivíduo constantemente agredido estimula no/a estudante lésbica, gay, bissexual e/ou trans (LGBT) o autocontrole de suas performances.

Talvez seja nesse dado que resida o maior desafio dos indivíduos LGBT na adolescência. Nesse período, marcado pela profunda demarcação de singularidade que se expressa nas vestimentas, nos acessórios, cabelos, estilos musicais e na radicalização de posição frente ao poder familiar e escolar, os/as estudantes acabam por controlar seu comportamento, gestos e relações sociais, se desejam permanecer na escola sem agressões cotidianas. Para alguns, o desejo é fortemente monitorado no ambiente escolar para não

\footnotetext{
${ }^{8}$ No jogo do bicho, o número 24 é atribuído ao animal "veado" e é costumeiro usá-lo para designar, de forma ofensiva, o homem. Veado ou "viado", nessa lógica, seria sinônimo de gay.
} 
MASCULINIDADES HEGEMÔNICAS E DISSIDÊNCIAS:

TENSÕES CURRICULARES EM COTIDIANOS DE ESCOLAS DA PERIFERIA

despertar nenhuma dúvida sobre a performance de gênero, conforme Daniel segue descrevendo:

Procuro não estar próximo quando os meninos começam a falar das garotas que saíram na festa. Por mais que eu invente, tenho medo de não acreditarem em mim. Na verdade, evito o contato com eles.

Semelhantemente, Luan, estudante da Escola Nós do Morro, afirma:

De vez em quando namoro algumas meninas na escola, pros caras não desconfiarem de $\operatorname{mim}$ (17 anos).

A descoberta do próprio universo do corpo e a mistificação da prática sexual são exercícios presentes na vida cotidiana de adolescentes e, em geral, são compartilhadas com os/as amigos/as. A necessidade de compartilhar experiências amorosas e de ouvir relatos sobre relações sexuais é o caminho que vários/as adolescentes utilizam para diferenciá-los das representações sobre a infância, suas brincadeiras e objetos atrelados a ela.

Para os estudantes gays e trans das escolas Nós do Morro e Vozes, o primeiro beijo, a paquera, a troca de números telefônicos e a publicidade do namoro, todas as experiências que romantizam a vida cotidiana de adolescentes, parecem não ocorrer sem excentricidades e/ou agressões. A prerrogativa da solidão, o autocontrole dos gestos e o silenciamento oral dos desejos foram as primeiras experiências que eles tiveram que aprender nas escolas.

Os indivíduos entrevistados relataram como começaram a perceber seus desejos afetivo-sexuais, sofrendo e tendo de enfrentar diversas dificuldades na escola:

Na escola, os colegas são os piores. Nas brincadeiras com os meninos, eles dizem: "Você não sabe brincar, vai brincar com as meninas". "Ah, vai brincar de boneca". Quando 0 professor me chama para ir ao quadro, aí começam as brincadeiras, né! Os palavreados, aquelas coisas... Eles me abordavam muito fora da sala de aula também, em qualquer lugar, bastava eu me manifestar que aí começava". (Pedro, 16 anos, Escola Vozes)

As narrativas acima elencadas, nos sugerem que as escolas são, em geral, um dos mais perversos espaços para um/a adolescente que performatiza marcadores sexuais contrahegemônicos. Questão reiterada por Britzman (1996; 2001), Sullivam, (1996) e Caetano (2011). Elas são cruéis não somente por nomear o indivíduo, mas por classificá-lo antes mesmo que ele tenha conhecimento sobre as redes de significados que se operam em sua classificação. 
Nas escolas investigadas, podemos perceber uma unidade entre heterossexualidade e masculinidade formando um vínculo que, pelo senso comum, parece naturalizá-la. Com isso, ao serem negadas outras possibilidades performáticas, o trabalho de produção de identidades se torna sistemático, acentuado pela preocupação de introduzir o menino ao mundo masculino hegemônico por meio da prática esportiva, do reconhecimento e da agressividade física, o domínio da racionalidade etc.

As experiências do estudante João e da estudante Dayse reatualizam as estratégias docentes afirmadas por Moita Lopes (2002, p. 155) quando diz que "os professores homens constantemente usam insultos sexuais como 'não seja mulherzinha' para garantir o desempenho da masculinidade hegemônica", conforme podemos observar:

Um professor de Matemática... me colocou em uma situação que eu não esperava, disse que só um homem resolveria o problema ... eu errei... e aí! Se fosse os colegas eu até esperava, a gente passa por cima ... mas professor... (João, 19 anos, Escola Nós do Morro)

Eu ia para a escola e a professora sempre me colocava ao lado dos meninos. É muito cômodo pros professores ... de um lado ou de outro, né? Então eu me sentia assim meio que excluída ... porque eu queria ficar do lado das meninas e me colocavam do lado dos meninos, mas, como me colocavam do lado dos meninos, eu estava me sentindo... excluída... para os professores, meu lugar era do lado dos meninos. Mas eu não queria, sempre soube que eu era uma menina, mesmo com os professores insistindo em dizer 0 contrário" (Dayse, 18 anos, Escola Vozes)

As narrativas de João e Dayse reforçam a ideia de que a escola, ao adotar o modelo binário de gênero e defender as expectativas sociais e sexuais a ele atreladas, acaba por ocultar, silenciar e marginalizar outras possibilidades performáticas que vivem na excentricidade desse jogo dicotômico. Nessas relações de poder, a depreciação das performances de lésbicas, gays e trans se dá, primeiramente, por meio do policiamento de gênero. A discriminação ocorre porque a escola participa da rejeição daqueles/as que vivem masculinidades (ou feminilidades) de formas diversas das hegemônicas. Dessa forma, contribuem para que tais sujeitos não sejam reconhecidos como homens e mulheres entendidos como de verdade (MISKOLCI, 2005), evidenciando o caráter homofóbico, lesbofóbico e transfóbico das práticas didático-curriculares da escola.

Observamos que as escolas, ao ignorarem as condições diárias de violências sofridas pelas/os estudantes LGBT, tornam-se um dos principais responsáveis pelas práticas educativas de perpetuação da homofobia. Essa afirmativa é bastante relevante, porque, a partir 
do momento em que a escola, com seus conhecimentos universalizados, adota uma ideologia heterossexista, seja pela negação da homossexualidade, travestilidade, transexualidade ou pelo silenciamento de suas existências, reforça os discursos trazidos de casa por aquela criança que aprendeu, no seio familiar, que essas identidades são "pecaminosas", "anormalidades" ou "erradas". Dessa forma, esse sujeito poderá, com o aval de uma escola que se exime da discussão de gênero/sexualidade, crescer acreditando na veracidade dessa informação e, ainda, dependendo da maneira como encaminhará sua sexualidade na fase adulta, o significado dessa construção social poderá ser desastroso para si e para a sociedade.

A desinformação agregada à insensibilidade e ao preconceito resultam quase sempre em violência aos/às estudantes LGBT. Nas escolas investigadas, a identidade sexual passou a ser corresponsabilizada pelo preconceito e violência física vivida por seus/suas estudantes. A culpa da violência sofrida recaiu sobre as ações e comportamentos dos/as estudantes, corresponsabilizando-os pela agressão sofrida. Entendemos que a violência, mais do que imprimir sofrimento ou destruição ao corpo físico e mental, tem por interesse arrancar a dignidade dos/as estudantes.

A nossa aproximação para desenvolver essa pesquisa e escrever esse artigo foi exatamente provocada pelas experiências que compartilhávamos nas escolas em que atuamos. Com ela, buscamos elaborar as estratégias possíveis de enfrentamento ao quadro de regulação sexual e de hostilidade e violência às dissidências sexuais em escolas distantes dos centros urbanos.

A localização das instituições educacionais nas periferias de dois municípios arrabaldes do grande centro da cidade do Rio de Janeiro e a ausência de ações dos movimentos sociais, sindicatos e de políticas públicas parecem corroborar para a situação de violências sofridas pelos estudantes. Essa pesquisa faz parte da estratégia possível adotada por dois professores em visibilizar o cenário de hostilidade vivido pelos/as estudantes.

Inúmeros/as autores/as (CAETANO, 2011; SILVA JR, 2014; MISKOLCI, 2005) descrevem as dificuldades que docentes têm em desenvolver didático-curricularmente temas correlacionados aos eixos "gênero", "sexualidade", "homossexualidades", "transexualidades" e "travestilidades", mesmo com as formações continuadas e o crescente aumento de disciplinas ofertadas nas licenciaturas ${ }^{9}$. Longe de ignorar as alterações cotidianas vividas nas

\footnotetext{
${ }^{9}$ Desde 2005, em parceria com as Instituições de Ensino Superior, o Ministério da Educação oferta formações nos temas gênero, sexualidade e relações étnico-raciais. Em 10 anos, foram formados mais de 60 mil gestores/as
} 
CAETANO, M. R. V.; JUNIOR, P. M. S.; GOULART, T. E. S.

escolas brasileiras a partir das demandas dos movimentos sociais e dos sujeitos da ação educativa (docentes e estudantes) ao Estado brasileiro e, por sua vez, a execução de políticas públicas de enfrentamento à homofobia, sexismo e racismo, as narrativas dos estudantes sinalizam que estamos ainda muito longe de desmantelar as violências diárias vividas nas escolas e, sem dúvida, os currículos universalizados ajudam para esse cenário.

\section{CONSIDERAÇÕES FINAIS}

A proposta central deste estudo foi refletir sobre a importância de a escola estar atenta às questões de gênero e sexualidades que, constantemente, indagam as práticas curriculares e produzem efeitos nas vidas dos sujeitos das ações educativas. Com a pesquisa, ao atuarmos nas escolas investigadas evidenciamos, de um lado, as tensões em torno das expectativas sexuais produzidas pelos currículos e estudantes, e de outro, os efeitos violentos desse cenário na vida de estudantes.

Nesses termos, o que a pesquisa nos indica é que a lógica aplicada nos currículos das Escolas Vozes e Nós do Morro está centrada em performances hegemônicas dos gêneros que, por sua vez, produzem e naturalizam relações complementares e assimétricas entre mulheres e homens. Essa situação não somente produz efeito na vida cotidiana de pessoas heterossexuais como legitimam, através do uso de violência, a segregação das identidades sexuais dissidentes. Desse modo, as identidades dissidentes, frequentemente negadas pelos currículos, passam a ser vistas como as "outras", como a "negação da identidade dominante", o que contribui, em muito, para a construção de identidades vulneráveis à violência (BRITZMAN, 1996).

Entretanto, ainda que sobre esses corpos, a todo momento, estejam sendo direcionadas forças que buscam, de um lado, incluí-los na norma hegemônica dos sexos e, de outro, na reiteração forçada da coerência heteronormativa, acreditamos que o próprio ato de se narrar a partir da escola, feito pelos/as estudantes, apresenta-se como uma possibilidade de disputar a profusão discursiva refletida/produzida com/pelos currículos sobre gênero, sexualidade e

e profissionais da educação. Dados obtidos pelo Sistema Eletrônico do Serviço de Informações ao Cidadão, do $\begin{array}{llllll}\text { Ministério da } & \text { Educação, } & \text { em } & \text { 2015.. }\end{array}$ <http://www.acessoainformacao.gov.br/sistema/Pedido/DetalhePedido.aspx?id=YV50IYv6wmU=>. Acesso em 10 de março de 2016. 
MASCULINIDADES HEGEMÔNICAS E DISSIDÊNCIAS:

TENSÕES CURRICULARES EM COTIDIANOS DE ESCOLAS DA PERIFERIA

educação. As narrativas parecem enunciar que, mesmo com toda a força das regulações e controles sexuais, os estudantes produzem modos possíveis de permanecer e disputar a escola.

\title{
MASCULINIDADES HEGEMÓNICAS Y DISIDENCIAS: TENSIONES CURRICULARES EN COTIDIANOS DE ESCUELAS DE LA PERIFERIA
}

\section{Resumen}

Las identidades (sexuales), en su relación con el espacio escolar, están diariamente tensionando y sufriendo la interpelación de los currículos. Considerando ese escenario, a partir de las contribuciones de las teorías de género y sexualidades y de la metodología de Observación Participante, ese artículo tuvo por objetivo cuestionar los modos como las masculinidades hegemónicas de dos escuelas públicas de la región de la Baixada Fluminense de Rio de Janeiro son performatizadas y interactúan con las identidades sexuales disidentes, a ejemplo de gays, travestis y transexuales (GT). Con los datos que subsidiaron el análisis, producidos a partir de prácticas docentes de las personas autoras, se buscó cuestionar los currículos con vistas a interrogarlos sobre los discursos que produjeron modos de subjetivación y enseñaron formas heteronormativas, complementarias y asimétricas de proyección de las identidades sexuales fuertemente interpeladas por las expectativas en torno a la(s) masculinidade(s) negra(s).

Palabras-clave: Currículos; Performances; Masculinidades; Disidencias

\section{HEGEMONIC AND DISSENTS MASCULINITIES: CURRICULUM'S TENSIONS IN PERIPHERY AT THE OUTSKIRTS' SCHOOLS}

\begin{abstract}
(Sexual) identities, in relation to their place within schools, are constantly producing tension and suffering from interpellation of curricula. Considering this scenario, from the contributions of the theories of gender and sexuality and participant observation methodology, this article aimed to question the ways in which hegemonic masculinities are performatized and interact with sexual dissidents identities such as gay and transgender (GT) in two public
\end{abstract}


CAETANO, M. R. V.; JUNIOR, P. M. S.; GOULART, T. E. S.

schools in the Baixada Fluminense, region of Rio de Janeiro. With the data that supported the analysis, produced from author`s teaching practices, we sought to question the curriculum with a view to interrogate them about the talks that produced modes of subjectivity and taught heteronormative, complementary and asymmetrical ways of projection of sexual identities heavily traversed by the expectations surrounding the black masculinity.

Keywords: Curricula; Performances; Masculinities; Dissent

\section{REFERÊNCIAS}

ARROYO, Miguel. Currículo, território em disputa. Petrópolis-RJ: Vozes, 2011.

BADINTER, Elisabeth. $X Y$. Sobre a Identidade Masculina. Rio de Janeiro: Nova Fronteira, 1993.

BAUMAN, Zygmunt. Identidade. Rio de Janeiro: Jorge Zahar, 2005.

BRITZMAN, Deborah. O que é esta coisa chamada amor. Educação e Realidade, 21(1):7196. jan./jun. 1996.

. Curiosidade, Sexualidade e Currículo. In. LOURO, Guacira L. O corpo educado: pedagogias da sexualidade. Belo Horizonte: Autêntica, 2001. p. 83-112.

BUTLER, Judith. Problemas de Gênero: feminismo e subversão da identidade. Rio de Janeiro: Civilização Brasileira. 2003.

. Cuerpos que importam: sobre los limites materiales y discursivos del "sexo". Buenos Aires: Paidós, 2010.

BRASIL. Lei 8.069, de 13 de Julho de 1990. Estatuto da Criança e do Adolescente. Brasília: Ministério da Justiça, 1990.

. Decreto Presidencial n 6135, de 26 de junho de 2007. Disponível http://www.planalto.gov.br/ccivil_03/_ato2007-2010/2007/Decreto/D6135.htm. Acesso em: 12 de Mar. 2016.

Disponível

Sistema Eletrônico do Serviço de Informações ao Cidadão. Ministério da Educação.

<http://www.acessoainformacao.gov.br/sistema/Pedido/DetalhePedido.aspx ?id=YV50IYv6w $\mathrm{mU}=>$. Acesso em: 10 de Mar. 2016.

CAETANO, Marcio. Gênero e Sexualidade: um encontro político com as epistemologias de vida e os movimentos curriculares. 2011. 228f. Tese de doutorado. PPGE/UFF, Niterói, 2011. 
MASCULINIDADES HEGEMÔNICAS E DISSIDÊNCIAS:

TENSÕES CURRICULARES EM COTIDIANOS DE ESCOLAS DA PERIFERIA

CONNELL, Raewyn. Políticas de masculinidade. Educação e Realidade - 20 (2): p. 185 $206 \mathrm{jul} / \mathrm{dez} .1995$.

CORREIA, Maria da Conceição Batista. A observação participante enquanto técnica de investigação. Pensar Enfermagem. Vol. 13 N², $2^{\circ}$ Sem/2009. Disponível em: < http://pensarenfermagem.esel.pt/files/2009_13_2_30-36.pdf> Acesso em: 16 de Out 2014.

FOUCAULT, Michel. História da sexualidade - a vontade de saber. Rio de Janeiro: ED. Graal, 1988.

GRAMSCI, Antonio. Os intelectuais e a organização da cultura. Rio de Janeiro: Civilização Brasileira, 1978.

HALBERSTAM, Judith. Masculinidades femenina. Barcelona: Egales, 2008.

MISKOLCI, Richard. Um corpo estranho na sala de aula. In: ABRAMOWICZ, Anete; SILVÉRIO, V. R. (Orgs.) Afirmando diferenças: Montando o quebra-cabeça da diversidade na escola. Campinas-SP: Papirus, 2005. p. 20-35.

MOITA LOPES, Luiz Paulo. da. Identidades fragmentadas: a construção discursiva de raça, gênero e sexualidade em sala de aula. Campinas, SP: Mercado das Letras, 2002.

MOREIRA, Antônio Flávio Barbosa. (Org.). Currículo: questões atuais. Campinas, SP: Papirus, 1997.

PENNYCOOK, Alastair. Performance and performativity. In: Transcultural Flows. Nova York: Routledge, 2007. P. 34-50. Global Englishes and

RODRÍGUEZ Magda. El feminismo francés de la diferencia. AMORÓS, Celia. In Historia de la teoría feminista. Madrid- ES: Instituto de Investigaciones Feministas de la Universidad Complutense de Madrid/Consejería de Presidencia, Dirección General de la Mujer, 1994. pp. 214-240.

SCHOEN-FERREIRA, Teresa Helena. Adolescência através dos Séculos. Psicologia: Teoria e Pesquisa. Abr-Jun 2010, Vol. 26 n. 2, pp. 227-234.

SILVA, Tomaz. Tadeu da. Documentos de identidade: uma introdução às teorias de currículo. Belo Horizonte: Autêntica, 1999.

SILVA JR, Paulo. Quando as questões de gênero, sexualidades, masculinidades e raça interrogam as práticas curriculares: um olhar sobre o processo de co/construção das identidades no cotidiano escolar. 2014, 236f. Tese de doutorado. PPGE/UFRJ, RJ, 2014.

SULLIVAN, Andrew. Praticamente normal: uma discussão sobre o homossexualismo. São Paulo: Companhia das Letras, 1996.

WELZER-LANG, Daniel. A construção do masculino: dominação das mulheres e homofobia. Estudos Feministas. Ano 9, no 461, 2/2001. p. 460-482. 
CAETANO, M. R. V.; JUNIOR, P. M. S.; GOULART, T. E. S.

WHO, World Health Organization. Young People's Health - a Challenge for Society. Report of a WHO Study Group on Young People and Health for All. Technical Report Series 731. Geneva: WHO, 1986.

Data de recebimento: $13 / 12 / 2015$

Data de aceite: 29/02/2016 